SIBYLLE

BAUMBACH

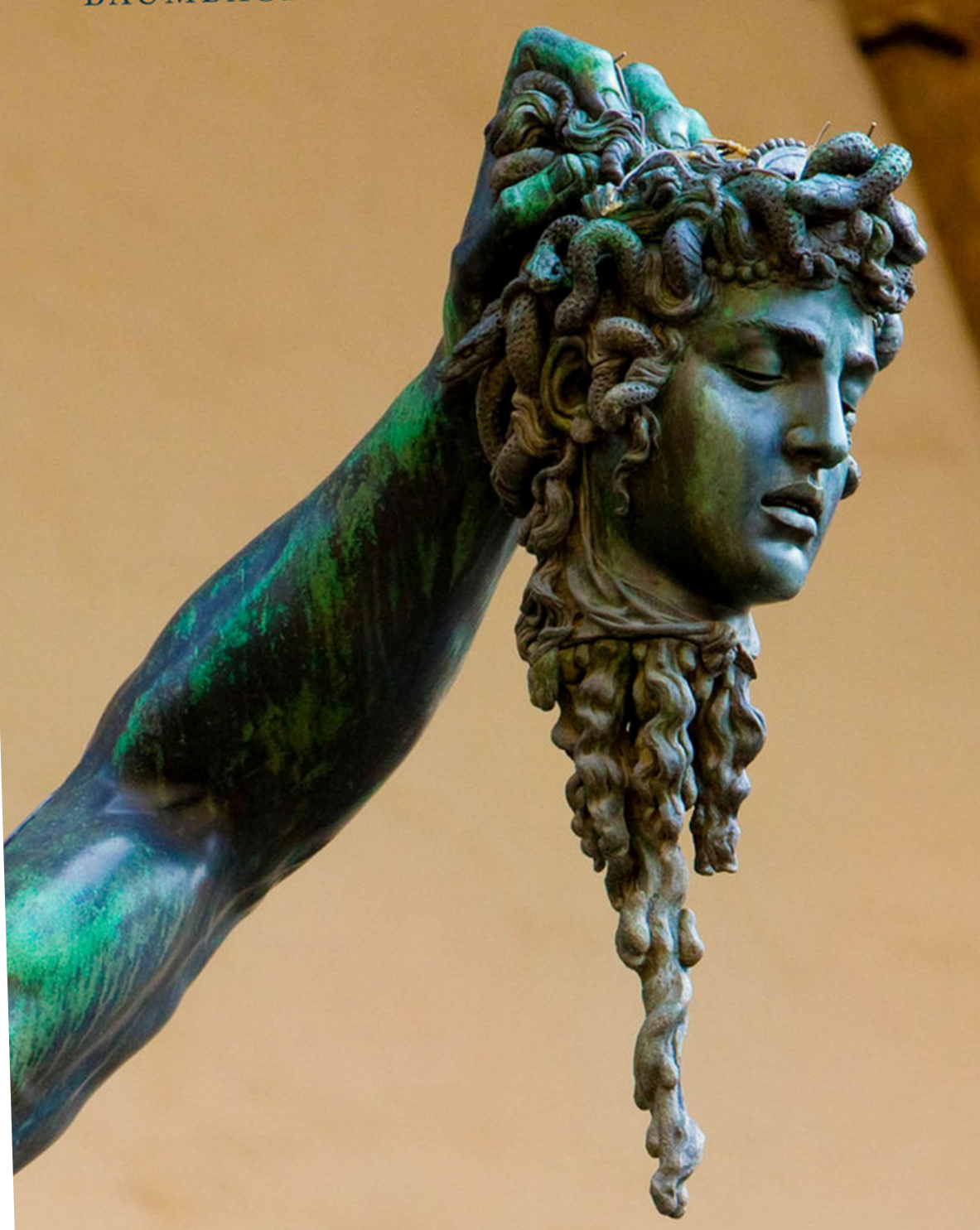

Literature

and

Fascination

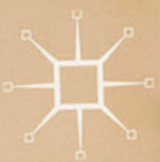




\section{Literature and Fascination}

Sibylle Baumbach

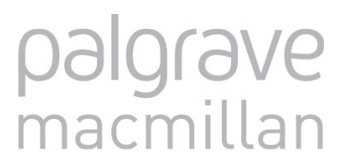




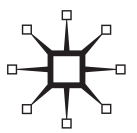

(c) Sibylle Baumbach 2015

All rights reserved. No reproduction, copy or transmission of this publication may be made without written permission.

No portion of this publication may be reproduced, copied or transmitted save with written permission or in accordance with the provisions of the Copyright, Designs and Patents Act 1988, or under the terms of any licence permitting limited copying issued by the Copyright Licensing Agency, Saffron House, 6-10 Kirby Street, London EC1N 8TS.

Any person who does any unauthorized act in relation to this publication may be liable to criminal prosecution and civil claims for damages.

The author has asserted her right to be identified as the author of this work in accordance with the Copyright, Designs and Patents Act 1988.

First published 2015 by

PALGRAVE MACMILLAN

Palgrave Macmillan in the UK is an imprint of Macmillan Publishers Limited, registered in England, company number 785998, of Houndmills, Basingstoke, Hampshire RG21 6XS.

Palgrave Macmillan in the US is a division of St Martin's Press LLC, 175 Fifth Avenue, New York, NY 10010.

Palgrave Macmillan is the global academic imprint of the above companies and has companies and representatives throughout the world.

Palgrave ${ }^{\circledR}$ and Macmillan ${ }^{\circledR}$ are registered trademarks in the United States, the United Kingdom, Europe and other countries.

ISBN 978-1-137-53800-0

This book is printed on paper suitable for recycling and made from fully managed and sustained forest sources. Logging, pulping and manufacturing processes are expected to conform to the environmental regulations of the country of origin.

A catalogue record for this book is available from the British Library.

Library of Congress Cataloging-in-Publication Data

Baumbach, Sibylle.

Literature and fascination / Sibylle Baumbach, W-1 Professor, Johannes

Gutenberg University Mainz, Germany.

pages $\mathrm{cm}$

Includes bibliographical references and index.

ISBN 978-1-137-53800-0

1. Literature-Psychology. 2. Mesmerism in literature. 3. Emotions in literature. 4. Memory in literature. I. Title.

PN49.B23 2015

809'.93384-dc23

2015013170

Typeset by MPS Limited, Chennai, India. 


\section{Contents}

Acknowledgements

viii

Introduction 1

1 Literature and Fascination $\quad 11$

$\begin{array}{ll}\text { Narratives of fascination } & 11\end{array}$

Of magic, love and envy: a short history of fascination 35

Fascination, myth and medusamorphoses 61

2 The Power of Magic and the Fear of Contamination:

Fascination in Early (Modern) Literature $\quad 71$

Fascination and meta-poiesis: the poet and his m(ed)use 71

The theatre of infection: fascination in Shakespeare's plays 85

3 Facing the Femme Fatale: The Poetics of Seduction

and the Fascination with Storytelling 114

$\begin{array}{ll}\text { The (non-)encounter with Medusa } & 121\end{array}$

The fascination with representation $\quad 128$

Tales and torments of narrative attraction 135

4 The Spark of Inspiration: Mesmerism, Electrifying

Fiction and Gothic Fascination $\quad 147$

The fascination with Frankenstein; or, The Modern Prometheus 147

Fascinating gazes, mesmeric energies and luring vampires 166

5 The Anxiety of Influence: Fascination with

$\begin{array}{ll}\text { the Self and the Other } & 190\end{array}$

Vampiric acts and Medusan powers $\quad 190$

$\begin{array}{ll}\text { The colonial stares back } & 208\end{array}$

6 The Gorgon Gazes Back: Contemporary Fascination 219

$\begin{array}{ll}\text { The Medusa effect } & 219\end{array}$

The fascination with terror: 9/11 novels 228

Reading for fascination 238

Conclusion: The Journey Ahead 252

Notes $\quad 255$

$\begin{array}{lr}\text { Bibliography } & 280\end{array}$

$\begin{array}{ll}\text { Index } & 309\end{array}$ 


\section{Introduction}

Fascination is a modern drug. It can tantalise and torment our imagination. It is at once intimately familiar and deeply mysterious. We recognise fascination instinctively, but it defies definition and eludes understanding. As a result, the term elicits an irresistible attraction:

Fascination! The very word itself almost fascinates, attracts. See it where we will, in book, pamphlet, or newspaper, it claims our attention. Do we hear it in lecture, speech or sermon, we listen more earnestly, eager to hear what is to follow. ${ }^{1}$

'Fascination' suggests a promise, even a guarantee for electrifying and mesmerising narratives, which captivate, hold us spellbound and make us crave for more. Especially in the media-saturated society of the twenty-first century, fascination has become the currency for success and satisfaction. Our desire to be enchanted by modern media, popular culture, literature, art and film is satiated by the entertainment industry. The popularity of fantasy and science fiction in literature and film, the proliferation of social media platforms and the rise of reality TV are but some examples of new literary and media genres that have emerged from our addiction to fascination.

Fascination operates with different degrees of 'presence'. While fantasy and science fiction make present what is absent, social platforms and reality TV supply a vicarious presence which supplants the desire for the authentic. Fascination culture therefore emerges as a nuanced and powerful force woven into the fabric of our culture and society. It lies at the heart of decision-making processes and strategies of consumer attachment. ${ }^{2}$

But what exactly are the ingredients of fascination? How does it connect to literature? What kinds of literary texts do people perceive as 'fascinating', and why? Does a universal understanding of fascination exist or is it a subjective, personal experience, whose rationale cannot be pinpointed? And if there are motifs and mechanisms that emerge to be particularly powerful 
for eliciting fascination in literature, how can these be conceptualised? By investigating the different forms and aesthetic functions of fascination in literature, this book explores what I refer to as 'narratives of fascination'. It identifies common markers of fascination and analyses how these are used for creating mechanisms which help draw readers into fictional worlds. I will argue that literature has become a key medium for communicating and discussing various concepts of fascination, while exploiting the concept to develop specific strategies of binding readers. It does so by means of medusamorphosis, a term which I introduce to define the backbone of narratives of fascination. Medusamorphosis relates to the mythical figure of the Gorgon Medusa, a key figure of fascination, whose looks were thought to turn living beings into stone. The Medusa incorporates the ambivalent forces of attraction and repulsion that are at the heart of the dangerously seductive and petrifying lure referred to as 'fascination'. Furthermore, the threat and thrill evoked by this figure support the conceptualisation of fascination and its development insofar as different representations of the Gorgon across historical eras, cultural contexts and across different media point to dominating trends underlying the dread of, or desire for 'fascination'.

Expanding on W. J. T. Mitchell's notion of the 'Medusa effect', ${ }^{3}$ which relates to the enchanting effects of images and their transmission into literary texts, this study explores the various ways in which literature resorts to concepts of fascination - as a constitutive force of literary and cultural narratives, as a key mechanism for eliciting attention and for regulating readers' responses to the possible worlds created by fiction. Whereas the Medusa effect does not always require the appearance of the Gorgon, the image of the dreaded snake-haired woman intensifies the theme and presence of fascination. I will argue that these various forms of medusamorphosis help conceptualise key strategies of literary fascination. The Medusa does not only serve as a cultural icon of fascination, suggesting a desire for fascination or even a fascination with fascination: she also allows us to rationalise the cognitive disorientation produced by simultaneous reactions of intense attraction and repulsion and alludes to the tension between presence and absence, which is constitutive of the Medusa effect.

As suggested by the Medusa effects identified in literature, art, photography and even in the context of university culture, ${ }^{4}$ fascination functions as a travelling concept ${ }^{5}$ insofar as it transcends different eras, cultural contexts, genres and knowledge systems and traverses disciplinary boundaries. Its decidedly interdisciplinary scope compels any comprehensive study of the concept to approach the phenomenon from multidisciplinary perspectives. These might encompass art history, film studies, media studies, sociology, musicology, psychology and also the neurosciences. This breadth of interdisciplinary coverage, however, would exceed the scope of this book. Instead, I will focus on literary fascination, supplemented by drawing on research approaches from adjacent disciplines - art history, film and media 
studies, psychology and cognitive studies. I will examine key trends and developments of narratives of fascination, its formative roles and various functions in different historical eras and socio-cultural contexts, and offer several in-depth case studies to substantiate these developments. These case studies are the backbone of this book and will yield insights into the complex mechanisms by which literature connects to discourses of fascination. As I will argue, these mechanisms transcend the historical and cultural contexts of the individual case studies insofar as fascination in literature has a universal common theme - its genome is the juxtaposition of attraction and repulsion.

While the opening quote of this chapter suggests that fascination is associated with positive experiences, this perspective is too narrow: fascination is a far more nuanced notion. It is often connected with the thrill arising from a lack of understanding, coupled with a desire for greater insight into the matter and an inner drive for knowledge, which resonates with what William Butler Yeats described as 'the fascination of what's difficult'. ${ }^{6}$ Furthermore, the term seems to bear an affinity to 'interest', to a trance-like state and to an overwhelming attraction. Movies, sports, images, stories and events are commonly perceived as 'fascinating' if they provoke surprise or astonishment in spectators; if they are pleasantly misleading and improbably challenge our worst expectations; if they lure us into an imagined realm that we did not know to exist.

The wonder we take in journeys to other (possible) worlds, the delight we experience in an unexpected, yet entertaining twist, or the cognitive challenges we confront when captured by detective narratives - these do not entirely define the intense reaction we recognise as 'fascination'. As this study serves to show, fascination is a borderline experience. It arises from the combination of two opposing forces and marks the concurrent awakening of deep attraction and intense repulsion. Borderline phenomena are especially powerful in eliciting fascination as they resist classification and occupy the vacuum between opposing aesthetic or ethical categories. Where ethics and aesthetics clash, fascination finds a fertile breeding ground. It is in this respect that aestheticised images of death, war atrocities or terrorist attacks can exert a disconcerting, yet irrepressible pull, which can only be described as fascination. Richard Drew's controversial photograph of the 'falling man', which shows one of the victims of the September 11 attacks, is a particularly poignant example of this ambiguous aspect of fascination. Aesthetically beautiful and ethically troubling, this image illustrates the complex blend of attraction and repulsion which composes fascination. It also indicates that fascination often occurs in connection with the forbidden, with images or events that are and should remain concealed.

Fascination is commonly associated with the mysterious, the disquieting and the obscure. These entail elements of anxious uncertainty and risk, and allude to the occult and mystic roots of the allotrope of fascination. Fascination 
relates to the ability of objects or people to resonate with our innate, hidden, subversive and potentially devious desires which are repressed in daily social interaction, but surface when we are confronted with images or practices of transgression that challenge ethical codes, aesthetic conventions or cultural norms. Some of the most effective fascination mechanisms arise in the nexus of our desire to witness a forbidden spectacle and our dread of its potentially dangerous repercussions.

\section{Fascination and literature}

Fascination is both culture-specific and culture-independent. What is considered forbidden or regarded as taboo is, of course, culture-dependent. These are, however, not static and immutable categories. On the contrary, the rapid changes of the category of the taboo are closely intertwined with the history of fascination which is both shaped by and shaping culture. While fascination draws on cognitive schemes and emotional tensions, it exceeds cultural specificities and temporal boundaries. This suggests that fascination can be conceptualised as the experience of thresholds and liminality caused by the cognitive irreconcilability of conflicting aesthetic categories and/or emotional reactions. Triggers of this cognitive disorientation include the antipodes of good and evil, terror and beauty, life and death, the familiar and the uncanny, the ugly and the beautiful. Consequently, fascination is at once an intra- and intercultural, a historical and transhistorical phenomenon. This is where literature comes into play. On the one hand, literature reacts to historical and cultural specificities, which it absorbs and reflects upon. On the other, it transcends cultural and historical boundaries, reflecting readers' prejudices, emotions and cognitive processes. This is the dual interplay of literature with fascination.

Fascination is virulent. It affects the mind and body of the individual and can also infect the collective. This is particularly true in the context of literature. On the one hand, the lure of literary texts seems restricted primarily to the individual experience of reading and processing narratives. On the other, the relative success of some texts, fuelled by marketing strategies, bestseller lists and literary canons, suggests that, even with regard to literary texts, which in the modern world are most commonly consumed in private, fascination can spread; or rather: it can be exploited as a marketing tool. As television and advertising do with modern audiences, literature serves to both sate and exploit our thirst for fascination.

Literature can also spread: it can be translated and traverse different cultural contexts, while retaining its fascination, as suggested by the canon of world literature. A comparative study of this phenomenon, which traces fascination across various (national) literary cultures, is yet to be conducted. Establishing the concept of medusamorphosis, the present book will focus on narratives of fascination in English literature and culture. Literature is also 
'infecting'. In fact, its infectious quality was frequently a matter of concern. The novel, with its mimetic quality, was often reproached for luring readers (predominantly women) into its narrative web. ${ }^{7}$ Similar anxieties were expressed with regard to drama and poetry. The passionate interactions of actors and spectators in theatre performance and the carefully constructed metrics, rhythms and rhymes of poetry were thought to elicit an intense aesthetic and potentially dangerous and enticing attraction.

While fascination ultimately is a highly individual, subjective experience, shaped by the historico-cultural environment, there are specific stimuli intimately associated with fascination which, in the literary context, can be traced across different genres and eras. Though subjective variations in the fascination experience must be accounted for, these stimuli might aid us in determining broader mechanisms of cultural selection. Following Gary Taylor, even though 'all stimuli are equal', 'some stimuli are more equal than others'.$^{8}$ One of the principal stimuli on the fascination scale is the intense focus on the visual, on the power of the eye and its poisonous rays, which can infect others by a mere glance. Recurrent motifs connected to imagery of vision such as the evil eye, the mirror or the forbidden gaze, for instance, as well as a deep investment in an irreducible aesthetic or ethical tension are characteristics of fascination that pervade literary texts which qualify as narratives of fascination.

Even though fascination is ubiquitous in our everyday culture, the concept itself is under-researched. Given the significant role of fascination in contemporary culture on the level of both production and reception aesthetics, this dearth of scholarly attention is all the more remarkable. Only recently have scholars begun to explore the phenomenon and provide first answers to questions of what literary fascination entails, how it is perceived, how it functions and how it evolved. ${ }^{9}$ Connecting to these studies, this book sets out to further analyse the pervasive role fascination played and continues to play in literary culture. The aim is to fill what still is a considerable research chasm and provide new perspectives on literary strategies of attraction and reader-response mechanisms. While this is not the only study that addresses the link between literature and fascination, it is the first one to explore the phenomenon as underlying literary strategy, tracing its forms and functions across different eras. The novelty of my approach consists in (a) its historical and theoretical scope, (b) its analysis of the connections between explicit and implicit integrations of concepts of fascination into literature and (c) its approach to the captivating powers of literary fascination via the Medusa motif and instances of medusamorphosis.

As I will show, the association of fascination with a desirable, even pleasurable experience is no specifically postmodern development. Despite the potential threats posed by fascination, as borderline phenomena, it has always been related to an eerie, yet enjoyable and even gratifying lure. This is indicated, for instance, by the enduring fascination with evil, which 
feeds on the intense attraction we feel towards the violation of ethical and aesthetic borders, and towards the experience of excess.

Popular examples of this fascination include biblical images of man's fall from grace or the seductive and satanic powers of the serpent as well as the strange attraction of fiendish figures, or the dangerous charm of the precariously seductive and highly eroticised femme fatale. This notion of an irresistible, yet somewhat disturbing appeal also surfaces in the fascination with the Other, the abject and the unknown. As suggested above, the pervasive fascination with images and texts produced during or in the aftermath of the traumatic events of 9/11 marks one of the most recent and most powerful examples of an unsettling and ethically troubling attraction caused by representations of terror. Much of their attraction stems from being able to vicariously participate in these gruesome events from the perspective of safe spectatorship. The security of witnessing a dangerous spectacle unharmed enables us to taste the threat of fascination without consequence, and then to return to our sheltered existence.

This study has two principal objectives: (a) to provide greater insight into the mechanisms underlying what I refer to as 'narratives of fascination' and (b) to discuss the extent to which narratives of fascination travel across temporal boundaries. One of the key concerns will be to explore the ways in which fascination has been shaping and continues to shape our (literary) culture(s).

To achieve this aim, the first part of the book will delineate the concept of fascination in general and literary fascination in particular. What do we mean when we speak of 'fascination' in literature? In what ways do the allotropes of fascination that surface in literary texts relate to the historicocultural contexts they occupy? I will provide answers to these questions by examining the cultural history of the term and its development in various media. The second and principal part of this book consists of detailed case studies of selected literary texts ranging from antiquity to the twenty-first century. These carefully chosen narratives of fascination will be analysed, juxtaposed with their historical development - from magical and magnetic attraction to the postmodern desire for presence - to rationalise and conceptualise their strong and enduring appeal.

The following questions will guide my analysis: do the themes and mechanisms of fascination support a universal 'language' or 'grammar' of attraction which underlies literary texts and which can be described as part of a greater aesthetics of fascination? How do literary narratives connect to, engage in or (critically) reflect upon discourses of fascination prevalent at the time of their production? Do these medusamorphoses, which constitute narratives of fascination, change in the course of their travels across temporal, cultural and generic boundaries? And, finally, drawing on Horst Bredekamp's concept of the 'picture act', ${ }^{10}$ can we attribute to literature a similar agency that allows literary text to return the gaze and look back at 
us, demanding an immediate response? This book answers these questions through selected case studies, which explore the ways in which literature deals with and mobilises discourses of fascination, while transporting and shaping concepts of fascination. I will argue that literature does not merely absorb cultural developments or dominant ideologies: rather, it emerges as a dominant player in the production and dissemination of these ideologies, evolving its own (critical) poetics of fascination.

Providing a detailed analysis of fascination as both a central theme and a key mechanism of literary narratives, used to trigger a specifically powerful reader response, this study offers fresh perspectives within the field of reception aesthetics. The analyses presented will be complemented by the assessment of the various mechanisms of fascination and popular concepts of attraction, which will be further explored in the attempt to rationalise the creation, representation and communication of fascination as an aesthetic tension between attraction and repulsion.

\section{Medusamorphoses: a roadmap}

Presenting 'fascination' as aesthetic reaction, Chapter 1 provides an overview of the concept and its history, tracing its travels across different eras and disciplines and distinguishing fascination from companion concepts. I will first offer a theoretical framework to explore 'narratives of fascination', discussing recent approaches to fascination and exploring its connection with recent research in the field of cognitive literary studies and affective narratology. I will then sketch the conceptual and historico-cultural history of the term. To examine key stratagems of literary fascination is a considerable challenge, as the concept underwent manifold changes: it takes its origin in witchcraft (fascinare - 'to bewitch'), enters theories of magnetism, mesmerism and (hypnotic) suggestion, and moves on to notions of charisma, psychoanalytic discourses and media theory. As this study will show, however, these different approaches to fascination share a common denominator, which is the powerful tension between attraction and repulsion. In the final part of this chapter, I will establish the connection between Medusa, literature and fascination, and introduce the concept of medusamorphosis for the following analysis.

The majority of the book will focus on literary case studies, which exemplify (meta-)fascination as theme and narrative strategy in chosen literary texts. As I will argue, these narratives do not only help promote and reflect upon specific implications and cultural values of fascination at the time of their production: they also use the irresistible attraction suggested by this concept (and, at least in earlier texts, even radiating from the sole use of the term) to draw readers in and absorb some of the captivating powers of fascination by integrating stimuli that lead to the same conflicting reactions associated with this intense aesthetic absorption. 
Chapter 2 is concerned with early examples of literary fascination. First, I will examine medusamorphoses in the love poetry of Catullus and in Dante Alighieri's influential epic The Divine Comedy, before considering a Medusa epigram by William Drummond. Catullus, whose poems to Lesbia contain the first recorded use of the term 'fascination' in literature, draws on the concept to allude to the widespread idea of love fascination, which binds the (predominantly male) lover to his (more rarely: her) beloved while stressing the infectious quality of words. In Dante, on the other hand, fascination emerges in the figures of the Furies and the Medusa. While the former explicitly appear in his Inferno, Medusa's presence is merely hinted at. Fascination arises from the tension between representation and elusiveness, which confirms the Gorgon's petrifying force and marks a powerful self-reflection of poiesis. In Drummond's epigram, this meta-reflective scope of the Medusa becomes even more apparent as the poem tricks its readers into performing various kinds of medusamorphoses, which confirm its luring power.

In the second part of this chapter, I will examine fascination as a significant, yet highly contested force of attraction in William Shakespeare's drama where it emerges in the context of iconoclastic criticism. The dangerous lure of the theatre arises from the combination of attraction and repulsion and especially from spectators' pleasure in continuously transgressing ethical, geographical and cultural boundaries. In their antitheatrical pamphlets, theatre opponents concentrated on emphasising the virulent quality of plays and actors, which were thought to poison spectators by their false play. This dangerous attraction, intensified by the notion of the forbidden, was at the heart of the theatre's enormous success. Shakespeare's plays draw on spectators' awareness of the potentially treacherous lure of fascination and include manifold medusamorphoses, opening up a complex meta-discourse on the powers and perils of fascination.

The third chapter explores the poetics of fascination in the poetry of Percy Bysshe Shelley, Dante Gabriel Rossetti, Samuel T. Coleridge and John Keats. Romanticism is deeply invested in fascination and its potential threats, as suggested by its strong interest in the enchanting powers of the femme fatale and mesmeric forces of poetry and storytelling. Shelley's 'On the Medusa of Leonardo da Vinci' and Rossetti's picture-poems 'Aspecta Medusa' and 'Lady Lilith' refer to the visual power of fascination and captivate readers through a continuous shift between verbal and visual media as they express a promise of fascination that is never redeemed. Pretending to protect readers from harmful images and the perilous lure of the femme fatale, these poems, just like Keats' 'La Belle Dame Sans Merci', turn out to exert the very same fascination they seem to be warding off. As I will show, the luring quality of these poetic narratives, which is at the core of Coleridge's mesmeric poem The Rime of the Ancient Mariner, derives from their investment in various kinds of medusamorphoses, both those that make explicit use of the Medusa 
figure and those that allude to her, presenting her as interwoven with their underlying imagery.

Chapter 4 turns to the novel and the Gothic tradition, which is deeply engaged in the aesthetics of fascination. Taking Mary Shelley's Frankenstein; or, The Modern Prometheus and Bram Stoker's Dracula as key examples, I will analyse this literary tension between attraction and repulsion in the context of magnetism, mesmerism and the newly discovered forces of electric as well as psychic energies, such as used in hypnosis, which coalesce in (pseudo-) scientific discourses of the time. In addition to distinguishing fascination from the uncanny, abject and the fantastic, this chapter focuses on the different notions of response-ability, aesthetic transgression and transmedial fascination, introducing both novels as intricate narratives of fascination which show a strong degree of introspection with regard to the absorbing powers of storytelling.

In Chapter 5 the 'anxiety of influence' associated with fascination in general and the fascination with the Other in particular will be analysed in Oscar Wilde's The Picture of Dorian Gray, his one-act play Salome and Joseph Conrad's Heart of Darkness respectively. While Wilde's novel serves as a case of a fascination elicited by the transgression of aesthetic and ethical boundaries, it also thematises the alluring power in the context of 'vampiric desire', which dominates art and also literature. The narrative develops a complex net of infectious influences, in which both the portrait and the yellow book serve as surrogates of medusamorphic powers. In the dangerously seductive Salome, Wilde conjures a figure whose attraction derives from the combination of repulsion and attraction and who is linked to Medusan powers in the final scene, which also reinforces the apotropaic powers of the theatre. Conrad's Heart of Darkness is introduced as a metafictional medusamorphosis, in which the fascination with the Other is complemented by the luring power of narrative energy. The novella provides a powerful example of medusamorphosis as it captivates the readers' and listeners' attention by (forbidden) sights and complex reflections upon its own narrative strategies by mirroring the narrative communication situation through integrated reader, or rather listener, responses.

Chapter 6 examines fascination in contemporary literature. It explores the roles of emerging trends and technologies of representation and reception in the digital age. As indicated in Sylvia Plath's poem 'Medusa', the Gorgon has developed into a multi-modal image that dominates postmodern communication culture. The threats and thrills of these prevailing Gorgonisms are exemplified in Tony Harrison's poem/film script The Gaze of the Gorgon, which attests to the imminent presence of Medusa in contemporary literature and culture. This persistence of narratives of fascination partly derives from aesthetic crises. One poignant example is the highly problematic attraction that arose in connection with the photographic image of the 'falling man', which is the driving force both in Don DeLillo's novel of 
the same title, and Jonathan Safran Foer's Extremely Loud and Incredibly Close. As suggested by the highly aestheticised, yet ethically deeply disturbing images of the terrorist attack, fascination in the twenty-first century concentrates on aesthetic and ethical tension. These will also be explored in connection with Ian McEwan's short stories, which draw a great deal of their attraction from ethical transgression and provide compelling examples of the medusamorphic quality of fiction.

I have deliberately selected a wide array of different texts and genres to explore genre-specific and genre-transgressive features of literary fascination and to examine the particular ways fascination is communicated in various literary contexts. As I argue, fascination is a concept that translates across these specificities. Despite the concept's historical variations, the underlying principle of fascination, that is, the tension between intense repulsion and deep attraction, remains intact across genres. Identifying some of the key mechanisms underlying narratives of fascination or medusamorphoses, this study makes a significant contribution to recent approaches in the field of literary aesthetics, cognitive literary studies and reader-response theories, and offers new readings of canonical texts. Fascination is not only a modern drug: it is the aesthetic glue that binds readers to literary texts and refers to the magic of literature that continues to captivate while leaving us yearning for 'more'. 